\title{
The initial factors affecting in-hospital mortality rate of patients undergoing surgery for post-traumatic extra-axial hematomas
}

\author{
Kulesza $\mathrm{B}^{1}$, Mazurek $\mathrm{M}^{1}$, Szmygin $\mathrm{P}^{1}$, Nogalski $\mathrm{A}^{2}$ \\ Chair and Department of Neurosurgery and Paediatric Neurosurgery, Medical University in Lublin. \\ Independent Public Clinical Hospital No. 4 in Lublin, Lublin, Poland. kuleszabartek88@gmail.com
}

\begin{abstract}
INTRODUCTION: Traumatic brain injury (TBI) is one of the most important causes of disability and death among young adults and referred to as "silent" epidemic. The most frequent consequences of a TBI are extra-axial hematomas, comprising of acute subdural $(\mathrm{SDH})$ and epidural hematoma (EDH). Most of the factors affecting the mortality have been analyzed in a wide group of TBI. The aim of this study is to identify factors affecting in-hospital mortality in patients undergoing surgery for acute traumatic subdural and epidural hematoma.

PATIENTS AND METHODS: The study included 128 patients operated on due to extra-axial hematomas. Twenty-eight patients were operated on for EDH and 100 on for SDH. Patients were treated at the Department of Neurosurgery Medical University in Lublin, during almost three years. The following factors were analyzed: demographic data, physiological factors, laboratory factors, computed tomography scan characteristics and time between the trauma and the surgery. All the factors were correlated with in-hospital mortality rate.

RESULTS: The univariate analysis has confirmed the influence of many factors affecting the in-hospital mortality.

CONCLUSION: It is interesting that factors such as GSC score, systolic blood pressure, respiratory rate and glycemia were associated with in-hospital mortality rate with highly statistically significant differences (Tab. 3 , Fig. 2, Ref. 40). Text in PDF www.elis.sk KEY WORDS: traumatic brain injury, epidural hematoma, subdural hematoma, factors, mortality.
\end{abstract}

\section{Introduction}

Head injury is one of the most important causes of disability and death among young adults. It is estimated that about sixtynine million people around the world experience traumatic brain injury (TBI) every year (1). The Center for Disease Control and Prevention described the TBI as a "silent” epidemic "of developed countries (2). One of the most common consequences of severe TBI are extra-axial hemorrhages, i.e. an acute subdural (SDH) and epidural hematoma (EDH). Treatment usually includes surgical removal of the hematoma (3). The prognosis after head injury is difficult to determine as it is captured in the Hippocratic aphorism, 'No head injury is too severe to despair of, nor too trivial to ignore' $(3,4)$. In hospital mortality rate after this type of injury is difficult to predict, but usually high. Most of the factors affecting mortality

\footnotetext{
${ }^{1}$ Chair and Department of Neurosurgery and Paediatric Neurosurgery, Medical University in Lublin. Independent Public Clinical Hospital No. 4 in Lublin, Lublin, Poland, ${ }^{2}$ Chair and Department of Trauma Surgery and Emergency Medicine, Medical University in Lublin, Independent Public Clinical Hospital No. 1 in Lublin Poland, Lublin, Poland
}

Address for correspondence: B. Kulesza, Chair and Department of Neurosurgery and Paediatric Neurosurgery, Medical University in Lublin. Independent Public Clinical Hospital No. 4 in Lublin, Jaczewskiego 8, 20-954 Lublin, Poland.

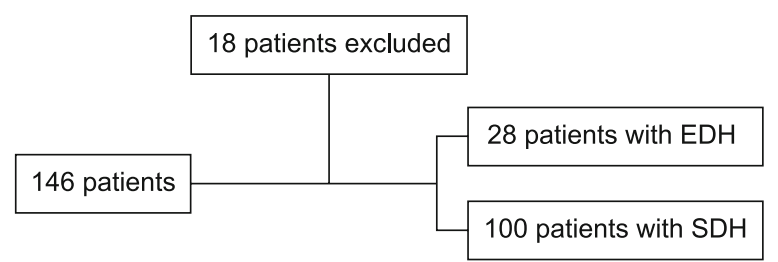

Fig. 1. Patients inclusion scheme.

have been analyzed in a broad group of TBI. There are few studies that analyze initial factors affecting TBI mortality complicated by extra-axial hematomas. The aim of this study is to identify factors affecting in-hospital mortality in patients undergoing surgery for acute traumatic subdural and epidural hematoma.

\section{Patients and methods}

Of all 146 patients operated on for extra-axial hematoma, 128 patients were included in the study. Two groups were formed, 100 patients were treated for acute subdural hematoma (SDH group), and 28 patients for epidural hematoma (EDH group). All patients were treated at the Department of Neurosurgery and Pediatric Neurosurgery of the Independent Public Clinical Hospital No. 4 (IPCH 
Tab. 1. Impact of factors on in-hospital mortality rate in the EDH group.

\begin{tabular}{|c|c|c|c|c|c|}
\hline Group of factors & Factors & & Death n (\%) & Alive n (\%) & $\mathrm{p}$ \\
\hline \multirow[t]{4}{*}{ Demographic data } & \multirow[t]{2}{*}{ Gender } & Men & $2(7.69 \%)$ & $24(92.31 \%)$ & \multirow{2}{*}{0.5} \\
\hline & & Women & $1(50 \%)$ & $1(50 \%)$ & \\
\hline & \multirow[t]{2}{*}{ Age } & $\leq 35$ years old & $0(0 \%)$ & $10(100 \%)$ & \multirow{2}{*}{0.47} \\
\hline & & $>36$ years old & $3(16.67 \%)$ & $15(83.33 \%)$ & \\
\hline \multirow[t]{12}{*}{ Physiological factors } & \multirow[t]{2}{*}{ GCS score } & 3-8 score GCS & $3(33.33 \%)$ & $6(66.67 \%)$ & \multirow{2}{*}{$0.03 *$} \\
\hline & & 9-15 score GCS & $0(0 \%)$ & $19(100 \%)$ & \\
\hline & \multirow[t]{2}{*}{ Pupil reaction } & Normal & $1(5.26 \%)$ & 18 (94.74\%) & \multirow{2}{*}{0.48} \\
\hline & & unreactive one or both & $2(22.22 \%)$ & $7(77.78 \%)$ & \\
\hline & \multirow[t]{2}{*}{ Saturation } & $>96 \%$ & $1(4.35 \%)$ & $22(95.65 \%)$ & \multirow{2}{*}{0.12} \\
\hline & & $\leq 96 \%$ & $2(40 \%)$ & $3(60 \%)$ & \\
\hline & \multirow[t]{2}{*}{ Systolic blood pressure } & 90-140 mmHg & $1(5.56 \%)$ & $17(94.44 \%)$ & \multirow[b]{2}{*}{0.58} \\
\hline & & $<89$ or $>141 \mathrm{mmHg}$ & $2(20 \%)$ & $8(80 \%)$ & \\
\hline & \multirow[t]{2}{*}{ Heart rate } & 60-120 pulse & $1(5 \%)$ & $19(95 \%)$ & \multirow[b]{2}{*}{$0.03 *$} \\
\hline & & $<59$ or $>121$ pulse & $3(37.5 \%)$ & $5(62.5 \%)$ & \\
\hline & \multirow[t]{2}{*}{ Respiratory rate } & 10-25 breaths per minute & $1(4.55 \%)$ & 21 (95.45\%) & \multirow[b]{2}{*}{0.2} \\
\hline & & $<9$ or $>26$ breaths per minute & $2(33.33 \%)$ & $4(66.67 \%)$ & \\
\hline \multirow[t]{14}{*}{ Laboratory factors } & \multirow[t]{2}{*}{ WBC } & $4.8-10.8 \times 10^{3} / \mathrm{mm}^{3}$ & $1(11.11 \%)$ & $8(88.88 \%)$ & \multirow[b]{2}{*}{0.54} \\
\hline & & $<4.7$ or $>10.9 \times 10^{3} / \mathrm{mm}^{3}$ & $2(10.53 \%)$ & $17(89.47 \%)$ & \\
\hline & \multirow[t]{2}{*}{ HGB } & $12-18 \mathrm{mg} / \mathrm{dl}$ & $2(9.52 \%)$ & $19(90.48 \%)$ & \\
\hline & & $<11 \mathrm{mg} / \mathrm{dl}$ & $1(14.29 \%)$ & $6(85.71 \%)$ & 0.72 \\
\hline & $\overline{\mathrm{PLT}}$ & $130-400 \times \times 10^{3} / \mathrm{mm}^{3}$ & $1(4.55 \%)$ & $21(95.45 \%)$ & \\
\hline & & $<129$ or $>401 \times 10^{3} / \mathrm{mm}^{3}$ & $2(33.33 \%)$ & $4(66.67 \%)$ & 0.20 \\
\hline & Glycaemia & $70-110 \mathrm{mg} / \mathrm{dl}$ & $0(0 \%)$ & $7(100 \%)$ & \\
\hline & & $>111 \mathrm{mg} / \mathrm{dl}$ & $3(14.29 \%)$ & $18(85.71 \%)$ & 0.72 \\
\hline & Sodium & $135-157 \mathrm{mEq} / \mathrm{It}$ & $1(4 \%)$ & $24(96 \%)$ & \\
\hline & & $<134 \mathrm{mEq} / \mathrm{It}$ & $2(66.67 \%)$ & $1(33.33 \%)$ & $0.02 *$ \\
\hline & Coagulopathy & $\mathrm{INR} \leq 1.2$ or $\mathrm{PT} \leq 12.7 \mathrm{~s}$ & $18(90 \%)$ & $2(10 \%)$ & \\
\hline & & INR $>1.3$ or $\mathrm{PT}>12.8 \mathrm{~s}$ & $7(87.5 \%)$ & $1(12.5 \%)$ & 0.85 \\
\hline & Ethanol & $\leq 0.5 \%$ & $1(11.11 \%)$ & $8(88.89 \%)$ & \\
\hline & & $>0.6 \%$ & $2(10.53 \%)$ & $17(89.47 \%)$ & 0.54 \\
\hline Computer Tomography & Skull fracture & Present & $2(10 \%)$ & $18(90 \%)$ & \\
\hline scan characteristics & & Absent & $1(12.5 \%)$ & $7(87.5 \%)$ & 0.63 \\
\hline & $\overline{\mathrm{SAH}}$ & Present & $3(27.27 \%)$ & $8(72.73 \%)$ & \\
\hline & & Absent & $0(0 \%)$ & $17(100 \%)$ & 0.10 \\
\hline & $\overline{\mathrm{IPH}}$ & Present & $1(6.25 \%)$ & $15(93.75 \%)$ & 070 \\
\hline & & Absent & $2(16.67 \%)$ & $10(83.33 \%)$ & 0.79 \\
\hline & $\overline{\mathrm{IVH}}$ & Present & $1(33.33 \%)$ & $2(66.67 \%)$ & \\
\hline & & Absent & $2(8 \%)$ & $23(92 \%)$ & 0.72 \\
\hline & Basal cistern & Normal size & $0(0 \%)$ & $9(100 \%)$ & \\
\hline & & Compressed and absent & $3(15.79 \%)$ & $16(84.21 \%)$ & $0.02 *$ \\
\hline & Hematoma thickness & $<30 \mathrm{~mm}$ & $1(5.56 \%)$ & $17(94.44 \%)$ & \\
\hline & & $>31 \mathrm{~mm}$ & $3(30 \%)$ & $7(70 \%)$ & 0.10 \\
\hline & $\overline{\text { MLS }}$ & $<10 \mathrm{~mm}$ & $0(0 \%)$ & $23(100 \%)$ & \\
\hline & & $>11 \mathrm{~mm}$ & $3(50 \%)$ & $3(50 \%)$ & $00.06^{*}$ \\
\hline Time injury - surgery & & $\leq 4$ hours & $1(14.29 \%)$ & $6(85.71 \%)$ & \\
\hline & & 5-9 hours & $2(15.38 \%)$ & $11(84.62 \%)$ & 0.51 \\
\hline & & $\geq 10$ hours & $0(0 \%)$ & $8(100 \%)$ & \\
\hline
\end{tabular}

...- normal value of physiological factors and reference values of laboratory factors * statistically significant value

4) in Lublin from 1.10.2014 to 31.08.2017. Exclusion criteria for the examined group of patients included: lack of complete medical documentation, incomplete laboratory tests, lack of computed tomography description of the head (Fig. 1).

All factors were collected retrospectively at the admission of patients at the emergency department (ED) IPCH 4 in Lublin. The following factors from the groups were analyzed: demographic data, physiological factors, laboratory factors, computed tomogra- phy scan characteristics and the time between trauma and surgery. The records were examined for demographic data, such as gender and age. Physiological factors included initial GCS, pupil reaction to light, saturation, systolic blood pressure (SBP), heart rate (HR) and respiratory rate (RR) (normal or abnormal value). Laboratory factors included the number of white blood cells (WBC), hemoglobin (HGB) value, number of platelets (PLT), glycemia value, sodium concentration, coagulopathy and alcohol levels. Laboratory 



Fig. 2. Subdural hematoma with midline shift of $14 \mathrm{~mm}$ and epidural hematoma with maximum thickness of $33 \mathrm{~mm}$.

factors, similarly to physiological factors, were analyzed on the basis of two groups: normal values and outstanding ones (Tab. 1). Additionally, the influence of coagulopathy and the state after alcohol intoxication on the prognosis were examined. Coagulopathy was defined as INR $>1.2$ or PT $>12.7$ s. For the state of intoxication, the alcohol concentration was higher than $0.5 \%$. Each patient included in the study had a computed tomography (CT) of the head as soon as it was possible. The study contained particular characteristics from the CT, such as the present skull fracture, subarachnoid hemorrhage (SAH), intraventricular hemorrhage (IVH), intraparenchymal hemorrhage (IPH), maximum thickness of the hematoma, midline shift (MLS) and obliteration basal cistern. Skull fracture, SAH, IVH and IPH were analyzed in two categories, either present or absent. The maximum hematoma thickness and MLS were calculated using the Ozirix version 2.5 program based on cross sections from the pre-operative CT scan (Fig. 2). Basal cisterns were examined in three categories, namely a normal size, the compressed one and the absent one. The last factor was the time between the injury and the surgery.

We investigated the in-hospitality mortality of patients at the time of discharge.

\section{Statistical analysis}

Statistical analysis correlated all of the factors with in-hospital mortality rate. The obtained results of the tests were subjected to statistical analysis. To compare two independent groups the Mann-Whitney U test was performed. The $\mathrm{Chi}^{2}$ homogeneity test was performed to detect differences in unrelated qualitative characteristics between the groups. The $\mathrm{Chi}^{2}$ independence test was adopted to investigate the existence of the relationship between the studied features. A significance level of $\mathrm{p}<0.05$ was assumed indicating the existence of statistically significant differences. The database and statistical research were based on the STATISTICA 13.0 computer software (StatSoft, Poland).

\section{Results}

\section{Groups characteristics}

The average age of patients in the SDH group $(57.86 \pm 18.26)$ was statistically significantly higher than in the EDH group (38.81 \pm 13.37 years $)(p=0.00001)$. In both groups, men were most often hospitalized. The GCS score among patients with SDH (median-6) was statistically significantly less points than in EDH group (median-11,5) $(\mathrm{p}=0.0006)$. Skull fractures were more often associated with patients with EDH (71.43 \%) than with SDH (30 \%), (p = 0.00007). The median thickness of the hematoma was significantly higher in the group of patients with EDH $(26.5 \mathrm{~mm})$ than in the group with SDH $(17 \mathrm{~mm})(\mathrm{p}=0.00004)$ (Tab. 2).

Impact of factors on in-hospital mortality rate in $\mathrm{EDH}$ I SDH group (Tabs 1 and 3)

\section{Demographic data}

In the EDH group in-hospital mortality rate was more frequent in case of women than men. Anyone who was 35 years old and less, didn't die during hospitalization in comparison with elderly patients (0 \% vs $16.67 \%$ ). In the SDH group, no significant dif-

Tab. 2. Demographic data in groups.

\begin{tabular}{llccccc}
\hline \multirow{2}{*}{$\begin{array}{l}\text { Demographic } \\
\text { data }\end{array}$} & Groups & \multicolumn{2}{c}{$\mathrm{ADH}(\mathrm{n}=28)$} & & \multicolumn{2}{c}{ SDH $(\mathrm{n}=100)$} \\
\cline { 3 - 4 } \cline { 7 - 8 } & & $\mathrm{n}$ & $\%$ & & $\mathrm{n}$ & $\%$ \\
\hline Sex & Female & 2 & 7.14 & & 14 & 14.00 \\
& Male & 26 & 92.86 & & 86 & 86.00 \\
\hline Age & under 60 years & 27 & 96.43 & & 56 & 56.00 \\
& over 60 years & 1 & 3.57 & & 44 & 44.00 \\
\hline
\end{tabular}


Tab. 3. Impact of factors on in-hospital mortality rate in the SDH group.

\begin{tabular}{|c|c|c|c|c|c|}
\hline Group of factors & Factors & & $\begin{array}{l}\text { Death } \\
\text { n (\%) }\end{array}$ & $\begin{array}{l}\text { Alive } \\
\mathrm{n}(\%)\end{array}$ & $\mathrm{p}$ \\
\hline \multirow[t]{4}{*}{ Demographic data } & \multirow[t]{2}{*}{ Gender } & Men & $40(46.51 \%)$ & 46 (53.49\%) & \multirow{2}{*}{0.45} \\
\hline & & Women & $5(35.71 \%)$ & $9(64.29 \%)$ & \\
\hline & \multirow[t]{2}{*}{ Age } & $\leq 60$ years old & $24(42.86 \%)$ & 32 (57.14\%) & \multirow{2}{*}{0.16} \\
\hline & & $>61$ years old & $21(47.73 \%)$ & $23(52.27 \%)$ & \\
\hline \multirow[t]{12}{*}{ Physiological factors } & \multirow[t]{2}{*}{ GCS score } & 3-8 score GCS & $41(68.33 \%)$ & 19 (31.67\%) & \multirow{2}{*}{$0.00001^{*}$} \\
\hline & & 9-15 score GCS & $4(10 \%)$ & $36(90 \%)$ & \\
\hline & \multirow{2}{*}{ Pupil reaction } & Normal & $14(31.11 \%)$ & $31(68.89 \%)$ & \multirow[b]{2}{*}{$0.01 *$} \\
\hline & & unreactive one or both & $31(56.36 \%)$ & $24(43.64 \%)$ & \\
\hline & \multirow{2}{*}{ Saturation } & $>96 \%$ & $13(27.66 \%)$ & 34 (72.34\%) & \multirow{2}{*}{$0.001^{*}$} \\
\hline & & $<96 \%$ & 32 (60.38\%) & 21 (39.62\%) & \\
\hline & \multirow{2}{*}{ Systolic blood pressure } & $90-140 \mathrm{mmHg}$ & $12(27.91 \%)$ & $31(72.09 \%)$ & \multirow{2}{*}{$0.0003^{*}$} \\
\hline & & $<89$ or $>41 \mathrm{mmHg}$ & 33 (57.89\%) & $24(42.11 \%)$ & \\
\hline & \multirow{2}{*}{ Heart rate } & 60-120 pulse & 35 (44.3\%) & $44(55.7 \%)$ & \multirow{2}{*}{0.78} \\
\hline & & $<59$ or $>121$ pulse & $10(47.62 \%)$ & $11(52.38 \%)$ & \\
\hline & \multirow[t]{2}{*}{ Respiratory rate } & 10-25 breaths per minute & $15(25.86 \%)$ & $43(74.14 \%)$ & \multirow{2}{*}{$0.00001^{*}$} \\
\hline & & $<9$ or $>26$ breaths per minute & $30(71.43 \%)$ & $12(28.57 \%)$ & \\
\hline \multirow{14}{*}{ Laboratory factors } & \multirow{2}{*}{ WBC } & $4.8-10.8 \times 10^{3} / \mathrm{mm}^{3}$ & $18(37.5 \%)$ & $30(62.5 \%)$ & \multirow{2}{*}{0.15} \\
\hline & & $<4.7$ or $>10.9 \times 10^{3} / \mathrm{mm}^{3}$ & $27(51.92 \%)$ & $25(48.08 \%)$ & \\
\hline & \multirow[t]{2}{*}{ HGB } & $12-18 \mathrm{mg} / \mathrm{dl}$ & 37 (46.84\%) & 42 (53.16\%) & \\
\hline & & $<11 \mathrm{mg} / \mathrm{dl}$ & $8(38.1 \%)$ & $13(61.9 \%)$ & 0.42 \\
\hline & PLT & $130-400 \times \times 10^{3} / \mathrm{mm}^{3}$ & $29(42.65 \%)$ & 39 (57.35\%) & \\
\hline & & $<129$ or $>401 \times 10^{3} / \mathrm{mm}^{3}$ & $16(50 \%)$ & $16(50 \%)$ & 0.49 \\
\hline & Glycaemia & $70-110 \mathrm{mg} / \mathrm{dl}$ & $0(0 \%)$ & 22 (100\%) & $000001 *$ \\
\hline & & $>111 \mathrm{mg} / \mathrm{dl}$ & $45(57.69 \%)$ & $33(42.31 \%)$ & 0.00001 \\
\hline & $\mathrm{Na}$ & 135-157mEq/It & 40 (44.94\%) & $49(55.06 \%)$ & 077 \\
\hline & & $<134 \mathrm{mEq} / \mathrm{It}$ & $5(45.45 \%)$ & $6(54.55 \%)$ & 0.17 \\
\hline & Coagulopathy & $\mathrm{INR} \leq 1.2$ or $\mathrm{PT} \leq 12.7 \mathrm{~s}$ & 37 (53.62\%) & 32 (46.38\%) & 068 \\
\hline & & INR $>1.3$ or $\mathrm{PT}>12.8 \mathrm{~s}$ & $18(58.06 \%)$ & $13(41.94 \%)$ & 0.00 \\
\hline & Ethanol & $\leq 0.5 \%$ & 35 (50.72\%) & $34(49.28 \%)$ & 009 \\
\hline & & $>0.6 \%$ & $10(32.26 \%)$ & $21(67.74 \%)$ & 0.09 \\
\hline Computer Tomography & Skull fracture & Present & $11(46.67 \%)$ & $16(53.33 \%)$ & 083 \\
\hline scan characteristics & & Absent & $31(44.29 \%)$ & $39(55.71 \%)$ & 0.05 \\
\hline & $\mathrm{SAH}$ & Present & $26(55.32 \%)$ & $21(44.68 \%)$ & \\
\hline & & Absent & 19 (35.85\%) & 34 (64.15\%) & 0.05 \\
\hline & $\mathrm{IPH}$ & Present & 19 (51.35\%) & $18(48.65 \%)$ & \\
\hline & & Absent & $26(41.27 \%)$ & 37 (58.73\%) & 0.33 \\
\hline & IVH & Present & $12(70.59 \%)$ & $5(29.41 \%)$ & $0.02 *$ \\
\hline & & Absent & $33(39.76 \%)$ & $50(60.24 \%)$ & $0.02^{\top}$ \\
\hline & Basal cistern & Normal size & $5(29.41 \%)$ & 12 (70.59\%) & $0.04 *$ \\
\hline & & Compressed and absent & $40(48.19 \%)$ & $43(51.81 \%)$ & $0.04^{\star}$ \\
\hline & Hematoma thickness & $<20 \mathrm{~mm}$ & $26(34.67 \%)$ & 49 (65.33\%) & $00007 *$ \\
\hline & & $>21 \mathrm{~mm}$ & $19(76 \%)$ & $6(24 \%)$ & $0.000 / x$ \\
\hline & MLS & $\leq 20 \mathrm{~mm}$ & 34 (39.54\%) & 52 (60.46\%) & \\
\hline & & $>21 \mathrm{~mm}$ & $11(78.57 \%)$ & $3(21.43 \%)$ & $0.005^{*}$ \\
\hline Time injury - surgery & & $\leq 4$ hours & $8(42.11 \%)$ & $11(57.89 \%)$ & \\
\hline & & 5-9 hours & $29(46.77 \%)$ & 33 (53.23\%) & 0.9 \\
\hline & & $\geq 10$ hours & $8(42.11 \%)$ & $11(57.89 \%)$ & \\
\hline
\end{tabular}

* statistically significant value

ferences between the gender and mortality were found $(p=0.45)$. The patients who were older than 60 years had a higher in-hospital mortality rate than the younger ones. No difference was statistically significant.

\section{Physiological factors}

In the EDH group, only patients after a severe head injury (GCS score 3-8) died during hospitalization in comparison with patients with GCS between 9-15 points. In the SDH group, the patients after a severe head injury had a significantly higher mortality rate than other. In EDH and SDH patients with non-reactive pupils, an abnormal value of pulse rate, saturation, systolic blood pressure and respiratory rate more often died during hospitalization than the patients with normal reactive pupils and other physiological factors. In EDH group only the difference regarding GCS score and HR was statistically significant $(p=0.03)$. In SDH group 
all of the differences were statistically significant except for heart rate. In SDH groups, case of GSC score, SBP, RR differences were highly statistically significant $(\mathrm{p}<0.0003)$.

\section{Laboratory factors}

Statistical analysis in EDH and SDH groups did not show a significant relationship between the number of WBC, the value of HGB, the presence of coagulopathy and in-hospital mortality. In case of sodium concentration statistical analysis showed that hyponatremia was associated with significantly higher mortality rate only in the EDH group ( $p=0.02)$. An abnormal number of PLT was associated with higher in-hospital mortality rate in both groups. In both groups the state after the alcohol intoxication was associated with smaller in-hospital mortality rate. The differences were not statistically significant. In both groups anyone with normoglycemia didn't die compared with the patients with hyperglycemia. Only in SDH group the differences were statistically significant $(\mathrm{p}<0.00001)$.

\section{Computer Tomography scan characteristics}

Patients with skull fracture in both groups more often died during hospitalization than patients without the fracture. Patients with the presence of traumatic SAH in both groups more often died during hospitalization than patients without SAH. In the case of the presence of IPH, only in the SDH group it was associated with higher in-hospital mortality rate. In both groups, patients with a present IVH more often died during hospitalization compared with patients with no ventricular bleeding. Only difference regarding present IVH was statistically significant in SDH group ( $\mathrm{p}=0.02$ ). In both groups the state of basal cisterns correlated with in-hospital mortality rate. Differences were statistically significant $(p=0.02$ and 0.04). In both groups, a greater maximum thickness of hematoma and MLS was associated with higher in-hospital mortality rate. Only in case of thickness of hematoma the difference wasn't statistically significant in the EDH group.

\section{Time injury-surgery}

No patient who waited for a surgery more than 10 hours died during hospitalization, compared to patients who waited for a surgery less than 10 hours. The difference wasn't statistically significant ( $p=0.51$ ). This is due to the fact that patients in good condition and without hematoma symptoms were operated on in the operating plan as a rule the next day. In the SDH group the statistical analysis did not find relationship between the time to surgery and in-hospital mortality.

\section{In-hospital mortality rate}

In patients with SDH, death during hospitalization was more frequent, it occurred in 45 out of 100 patients (45 \%) compared to the group with EDH, where it occurred in 3 out of 28 patients (10.71\%). The difference was statistically significant $(\mathrm{p}=0.0009)$.

Table 1. Impact of factors on in-hospital mortality rate in the EDH group

Table 3. Impact of factors on in-hospital mortality rate in the SDH group

\section{Discussion}

\section{Demographic data}

Age is one of the most powerful independent prognostic factor (5) and increasing age was associated with a worse outcome and higher mortality $(3,6)$, creating approximately linear function (7). The authors studying patients with extra-axial hematoma also found that increasing age was associated with a worse outcome and higher mortality rate $(3,8,9,10)$. In our study in ADH and $\mathrm{SDH}$ group increasing age was associated with higher mortality rate too. Though, differences weren`t statistically significant.

Gender did not affect the prognosis in TBI $(5,11)$. In the EDH group the ratio of women to men was 14:1. A similar ratio 14.3:1 was found by Ndoumbe et al (12). In the EDH group women had higher in-hospital mortality rate than men, $(p=0.5)$, which resulted from the fact that in the group women were much older than men $(49.5+13.44$ vs $38+13.27)$. Leitgeb et al observed a similar relationship in relation to the outcome (13). Authors examining patients operated on for SDH have proved that gender was nit related with mortality $(10,14)$. In the SDH group, no significant differences between the gender and in-hospital mortality rate were found too.

\section{Physiological factors}

The Glasgow Coma Scale (GCS) is the most common scale for assessing the patient's state of consciousness after a head injury. The age followed by the GCS motor score and the pupil response are most powerful independent prognostic factor after TBI $(5,15)$ especially with extra-axial hematomas $(3,14)$. In both groups GCS score was associated with in-hospital mortality with a statistically significant difference.

TBI causes paroxysmal sympathetic hyperactivity (PSH) manifested by increases in sympathetic activity involved in heart rate, blood pressure, respiratory rate and other. PSH has been reported in $33 \%$ patients suffering from severe TBI and associated with poorer outcome $(16,17)$. Hypoxia and hypotension following TBI are recognized as a significant secondary disorder associated with a poor outcome (18). Hypoxia causes rapid destruction of brain tissue and it is important to prevent hypoxia. Similarly, in the case of hypotension, recent guidelines recommend maintaining systolic blood pressure above $90 \mathrm{~mm} \mathrm{Hg}$ to optimize prognosis after TBI. Additionally, the results of randomized controlled studies showed that the increase in pressure should be maintained in people with normal blood pressure up to $140 \mathrm{~mm}$ $\mathrm{Hg}(19,20)$. Petroni et al found that hypotension (SBP $<90 \mathrm{~mm}$ $\mathrm{Hg}$ ) was associated with $90 \%$ mortality rate (21). Kalayci et al studied patients undergoing craniectomy for SDH and found that a saturation less than or equal to $96 \%$ was significantly associated with mortality rate $(p=0.004)(22)$. Respiratory rate higher than 25 and lower than 10 increased mortality rates. Similarly, heart rate value beyond a normal range is associated with a poor outcome in TBI (23). In our study, these factors were associated with mortality, especially in the SDH group where in the case GSC score, SBP and RR differences were highly statistically significant $(\mathrm{p}<0.0003)$. 


\section{Laboratory factors}

Laboratory factors routinely recorded on admission following TBI had a predictive value. Hyperglycemia is associated with a poorer outcome and is included to secondary insult in TBI (24). Early monitoring of blood glucose in the range of $80-110 \mathrm{mg} / \mathrm{dl}$ can protect against nerve ischemia damage, reduce disability and improve patient prognosis (25). In our study, nobody with normoglycemia died during hospitalization compared to patients with hyperglycemia. The presence of coagulopathy is a major death factor among patients suffering from traumatic intracranial hemorrhage. Platelets count and prothrombin time are of particular importance $(19,24,26)$. Fujii et al found that lower INR I and PTT are associated with better outcome than higher values (27). Sodium revealed a U-shaped relationship with outcome, hyper and hyponatremia are associated with poorer outcomes. However, hyponatremia is more strongly connected with poorer outcome $(19,24)$. In the EDH group hyponatremia was associated with higher mortality rate $(\mathrm{p}=$ 0.02). Hemoglobin and platelets low values were associated with a poorer outcome, on the other hand leukocytosis was associated with poorer outcome too (24). In our study the statistical analysis did not show a significant relationship between hemoglobin concentration and number of white blood cells and in-hospital mortality. Alcohol intoxication can reduce the mortality after TBI but it remains uncertain $(28,29)$. In our study, alcohol intoxication was associated with lower in-hospital mortality, but both differences weren`t statistically significant. Neuroprotective properties of alcohol require further investigation (28).

\section{Computer Tomography scan characteristics}

Computer tomography scan after TBI provides an objective assessment of a structural damage to the brain and can help in predicting prognosis $(3,19)$. There is strong evidence that greater

midline shift and the thickness of hematoma are associated with a higher mortality rate, our results also confirm that (30, 31, 32). Our analysis in both groups shows that skull fracture is associated with higher mortality rate, without the differences being statistically significant $(\mathrm{p}=0.63$ and $\mathrm{p}=0.84)$. The presence of a skull fracture confirms that the injury had to be caused by high force (33). Fracture of the skull in patients with TBI is associated with an increased risk of hemorrhagic intracranial lesions, which may require surgery (34). However, some energy is absorbed by the skull when the skull is damaged and, as a consequence, the brain is not exposed to full impact force (19). The presence of a IVH and traumatic SAH predicts higher mortality $(9,13,32)$. The patients with the presence of traumatic SAH and IVH more often died during hospitalization than the patients without SAH and no ventricular bleeding, in our both groups. In the EDH and SDH groups state of basal cisterns correlated with in-hospital mortality rate, with differences being statistically significant ( $p=0.02$ and $0.04)$. This has also been noticed by other authors $(5,7,35,36)$.

\section{Time injury-surgery}

Authors which study patients with EDH, found the most important prognostic factor is time between the trauma and surgery. Reduction of this time to a minimum can reduce mortality to zero
(11). Seelig et al. found that surgery up to 4 hours after injury reduced mortality from 90 to $30 \%$ among patients with SDH (37). According to Matsushima et al. performing surgery up to $200 \mathrm{mi}-$ nutes after arrival at the emergency department is associated with significantly lower in-hospital mortality $(p=0.03)(38)$. However, there are a few studies that didn`t find relation between a shorter time between injury-surgery and the mortality $(13,39)$. Although our statistical analysis wasn't associated with a significant relationship between time to surgery and in-hospital mortality rate, but it was reasonable to perform a surgery as soon as it is possible.

\section{In-hospital mortality}

The mortality rate among patients after surgery for EDH ranged from $2.6 \%$ to $15.5 \%$, the average ratio is about $10 \%(11,12,40)$. In case of SDH mortality rate varies from 22 to $75 \%$, most often the results oscillate around $40 \%(9,22,40)$. In our study mortality rate were $10.7 \%$ in the $\mathrm{EDH}$ group and $45 \%$ in the SDH group, and the difference was statistically significant, $(p=0.0009)$.

\section{Conclusion}

To the best of our knowledge, this is one of the few studies analyzing factors affecting mortality among patients operated on due to non-axial hematomas. This study confirmed the impact of many different factors on hospital mortality. Interestingly, factors such as GSC score, SBP, RR and hyperglycemia were associated with inhospital mortality, with highly statistically significant difference ( $\mathrm{p}$ $<0.0003$ ). In addition to the GCS score, other factors can be effectively treated at the place of an accident, which can help to achieve a better outcome. These results require confirmation in other studies in a larger group of patients. This study has a significant limitation such as small number of patients, especially the ones operated due to epidural hematomas and not including other routine factors to the examination at admission such as C-reactive protein, D-dimer.

\section{References}

1. Dewan MC, Rattani A, Gupta S et al. Estimating the global incidence of traumatic brain injury. J Neurosurg 2018: 1-18. https://doi. org/10.3171/2017.10.JNS17352.

2. Traumatic Brain Injury in the United States A Report to Congress. Centre for Disease Control and Prevention; Atlanta, GA, 2001.

3. Kulesza B. Mazurek M, Nogalski A, Rola R. Factors with the strongest prognostic value associated with in-hospital mortality rate among patients operated for acute subdural and epidural hematoma. Eur J Trauma Emerg Surg (2020). https://doi.org/10.1007/s00068-020-01460-8.

4. Steyerberg EW, Mushkudiani N, Perel P et al. Predicting Outcome after Traumatic Brain Injury: Development and International Validation of Prognostic Scores Based on Admission Characteristics. J Neurotrauma 2005; 22 (10): 1025-1039.

5. Murray GD, Butcher I, McHugh GS et al. Multivariable prognostic analysis in traumatic brain injury: results from the IMPACT study. J Neurotrauma 2007; 24 (2): 329-337.

6. Lingsma HF, Roozenbeek B, Steyerberg EW, Murray GD, Maas AI. Early prognosis in traumatic brain injury: from prophecies to predictions. Lancet Neurol 2010; 9 (5): 543-554. 
7. MRC CRASH Trial Collaborators, Perel P, Arango M et al. Predicting outcome after traumatic brain injury: practical prognostic models based on large cohort of international patients. BMJ 2008; 336 (7641): 425-429.

8. Jeong YH, Oh JW, Cho S, Korean Trauma Data Bank System Committee. Clinical Outcome of Acute Epidural Hematoma in Korea: Preliminary Report of 285 Cases Registered in the Korean Trauma Data Bank System. Korean J Neurotrauma 2016; 12 (2): 47-54.

9. Leitgeb J, Mauritz W, Brazinova A, Janciak I, Majdan M, Wilbacher I, Rusnak M. Outcome after severe brain trauma due to acute subdural hematoma. J Neurosurg 2012; 117 (2): 324-333.

10. Baucher G, Troude L, Pauly V, Bernard F, Zieleskiewicz L, Roche PH. Predictive factors of poor prognosis after surgical management of traumatic acute subdural hematomas: a single-center series. World Neurosurg. 2019; 126: e944-e952. https://doi.org/10.1016/j.wneu.2019.02.194

11. Khaled CN, Raihan MZ, Chowdhury FH. Surgical management of traumatic extradural hematoma: Experiences with 610 patients and prospective analysis. Ind J Neurotrauma 2008; 2: 75-79.

12. Ndoumbe, A, Ekeme MP, Jemea B, Simeu Ch, Takongmo S. Epidemiological Analysis of Surgically Treated Acute Traumatic Epidural Hematoma. Open J Modern Neurosurg 2016: 6; 89-97.

13. Leitgeb J, Mauritz W, Brazinova A, Majdan M, Wilbacher I. Outcome after severe brain trauma associated with epidural hematoma. ArchOrthop Trauma Surg 2013; 133 (2): 199-207.

14. Han MH, Ryu JI, Kim CH, Kim JM, Cheong JH, Yi HJ. Radiologic findings and patient factors associated with 30-day mortality after surgical evacuation of subdural hematoma in patients less than 65 years old. J Korean Neurosurg Soc 2017; 60: 239-249.

15. Bao L, Chen D, Ding L, Ling W, Xu F. Fever burden is an independent predictor for prognosis of traumatic brain injury. PLoS ONE 2014; 9: e90956. DOI: 10.1371/journal.pone.0090956.

16. Baguley IJ, Perkes IE, Fernandez-Ortega JF, Rabinstein AA, Dolce G, Hendricks HT; Consensus Working Group. Paroxysmal sympathetic hyperactivity after acquired brain injury: consensus on conceptual definition, nomenclature, and diagnostic criteria. J Neurotrauma 2014; 31:1515-20. 10.1089/neu.2013.3301

17. Zheng RZ, Lei ZQ, Yang RZ, Huang GH, Zhang GM. Identification and Management of Paroxysmal Sympathetic Hyperactivity After Traumatic Brain Injury. Front Neurol. 2020; 25; 11: 81. DOI: 10.3389/fneur.2020.00081

18. McHugh GS, Engel DC, Butcher I et al. Prognostic value of secondary insults in traumatic brain injury: results from the IMPACT study. J Neurotrauma 2007; 24 (2): 287-293.

19. Kulesza B, Litak J, Grochowski C, Nogalski A, Rola R. The Initial Factors with Strong Predictive Value in Relation to Six-Month Outcome among Patients Operated due to Extra-Axial Hematomas. Diagnostics 2020; 10 (3): 174. https://doi.org/10.3390/diagnostics10030174.

20. Chakraborty S, Skolnick B, Narayan RK. Neuroprotection trials in traumatic brain injury. Current Neurology and Neuroscience Reports 2016. https://doi.org/10.1007/s11910-016-0625-X.

21. Petroni G, Quaglino M, Lujan S et al. Early prognosis of severe traumatic brain injury in an urban argentinian trauma center. J Trauma 2010; 68: 564-570.

22. Kalayci M, Aktunç E, Gül S, Hanci V, Edebali N, Cagavi F, Açikgöz B. Decompressive craniectomy for acute subdural haematoma: An overview of current prognostic factors and a discussion about some novel prognostic parametres. J Pak Med Assoc 2013; 63: 34-49.

23. Saadat S1, Akbari H, Khorramirouz R, Mofid R, Rahimi-Movaghar V. Determinants of mortality in patients with traumatic brain injury. Ulus Travma Acil Cerrahi Derg 2012; 18 (3): 219-224.
24. Van Beek JG, Mushkudiani NA, Steyerberg EW et al. Prognostic value of admission laboratory parameters in traumatic brain injury: results from the IMPACT study. J Neurotrauma 2007; 24 (2): 315-328.

25. Tang J, Zhou LM, Jiang H. The roles and administration methods of insulin in the early treatment of acute brain injury. Zhongguo Yishi Zazhi 2012; 14: 1472-1474.

26. Joseph B, Aziz H, Zangbar B et al. Acquired coagulopathy of traumatic brain injury defined by routine laboratory tests: Which laboratory values matter? J Trauma Acute Care Surg 2014; 76 (1): 121-125.

27. Fujii T, Moriel G, Kramer DR, Attenello F, Zada G. Prognostic factors of early outcome and discharge status in patients undergoing surgical intervention following traumatic intracranial hemorrhage. J Clin Neurosci 2016; 31: 152-156.

28. Shandro JR, Rivara FP, Wang J, Jurkovich GJ, Nathens AB, MacKenzie EJ. Alcohol and risk of mortality in patients with traumatic brain injury. J Trauma 2009; 66: 1584-1590.

29. Plurad D, Demetriades D, Gruzinski G et al. Motor vehicle crashes: the association of alcohol consumption with the type and severity of injuries and outcomes. J Emerg Med 2010; 38: 12-17.

30. Gurer B, Kertmen H, Yilmaz ER, Dolgun H, Hasturk AE, Sekerci Z. The Surgical Outcome of Traumatic Extraaxial Hematomas Causing Brain Herniation. Turk Neurosurg 2017; 27 (1): 37-52.

31. Hamed M, Schuss P, Daher FH, Borger V, Güresir Á, Vatter H, Güresir E. Acute traumatic subdural hematoma: surgical management in the presence of cerebral herniation - a singlecenter series and multivariate analysis. World Neurosurg 2016; 94: 501-506.

32. Maas AI, Steyerberg EW, Butcher I et al. Prognostic Value of Computerized Tomography Scan Characteristics in Traumatic Brain Injury: Results from the IMPACT Study. J Neurotrauma 2007; 24 (2): 303-314.

33. Balik V, Lehto H, Hoza D et al. Post-traumatic frontal and parietooccipital extradural haematomas: a retrospective analysis of 41 patients and review of the literature. Cent Eur Neurosurg 2011; 72 (4): 169-175.

34. Muñoz-Sánchez MA, Murillo-Cabezas F, Cayuela-Domínguez A, Rincón-Ferrari MD, Amaya-Villar R, León-Carrión J. Skull fracture, with or without clinical signs, in mTBI is an independent risk marker for neurosurgically relevant intracranial lesion: a cohort study. Brain Inj 2009; 23: 39-44.

35. Bhaskar Naidu P, Truman Srinivas M, Selvakumar K. Computed tomography predictors for in-hospital mortality in severe and moderate head injury patients. Inter Surg J 2016; 3 (3): 1306-1309.

36. Krbila S, Waczulikova I, Sobona V, Zahorec R. Impact of intracranial pressure measurement on survival in patients with severe traumatic brain injury. Bratisl Med J 2013; 114 (12): 696-701

37. Seelig JM, Becker DP, Miller JD, Greenberg RP, Ward JD, Choi SC. Traumatic acute subdural hematoma: major mortality reduction in comatose patients treated within four hours. N Engl J Med 1981; 304: 1511-1518.

38. Matsushima K, Inaba K, Siboni S et al. Emergent operation for isolated severe traumatic brain injury: Does time matter? J Trauma Acute Care Surg 2015; 79: 838-842.

39. Sergides IG, Whiting G, Howarth S, Hutchinson PJ. Is the recommended target of 4 hours from head injury to emergency craniotomy achievable? Brit J Neurosurg 2006; 20: 301-305.

40. Tallon JM, Ackroyd-Stolarz S, Karim SA, Clarke DB. The epidemiology of surgically treated acute subdural and epidural hematomas in patients with head injuries: a population-based study. Can J Surg 2008; 51: 339-345.

Received April 15, 2020. Accepted May 8, 2020. 